\title{
Thinking on Training Mode of Developmental, Interdisciplinary and Innovative Talents
}

\author{
Hang Yuan \\ Guangzhou City construction College, Guangzhou, 510925, China
}

Keywords: Developmental. Interdisciplinary. Innovative. Talent mode

\begin{abstract}
With the arrival of the era of knowledge-driven economy, the training of developmental, interdisciplinary and innovative talents with strong adaptive capacity has become the emphasis of talent demand in the current era. How to train high-level developmental, interdisciplinary and innovative talents to adapt to the need of development of the current situation becomes an important issue in Chinese educational field. This paper respectively thinks about training mode of development, interdisciplinary and innovative talents.
\end{abstract}

\section{Introduction}

Talent issue is a priority among priorities concerning the future career development of the country. Institutions of higher learning are main places for training high-quality talents. The process of talent training is an extremely complicated systematic project, mainly involving factors in economy, politics, society and culture. In particular, under the new situation of rapid development of science and technology and world economic integration currently, the value orientation of talents shows a diversification trend. Educational and teaching methods of institutions of higher learning reflect the characteristic of diversification. It is required to establish and improve modern talent training system adapting to various talent characteristics and the promotion of integrated development of human beings, adapt to the objective of training developmental, interdisciplinary and innovative talents under new requirements and provide solid guarantee for the implementation of the strategy of reinvigorating China through human resource development.

\section{Thinking on training mode of developmental talents}

Developmental talents refer to new talents with high quality required under the new situation, spirit of innovation and sustainable development ability. Sustainable development mainly refers to delayed effect of development, innovation thought and innovation ability of college graduates after they take a post.

The training mode of developmental talents can be summarized as below: first, improve academical quality. It is required to create a dense academic research atmosphere, allow college students to develop a good learning style of diligence, studiousness, intensive study and thirst for knowledge and participate in various academic activities more consciously during the study so as to feel the rigorous spirit, personal charm and manner of academic leaders and masters in this subject in person and gradually train their strong will of devoting themselves to the development of scientific and cultural undertakings. Second, train humanistic spirit. The intersection and penetration of natural science and humanities have become an irresistible trend of contemporary scientific and technological development. Students of science and engineering should constantly improve their humanistic quality and students of liberal arts should learn some knowledge of science appropriately, thus realizing the combination of liberal arts and science and integration of major. Third, conduct classroom teaching well. In the process of classroom teaching in colleges and universities, teachers should positively transform their educational concept so as to adapt to the need of training developmental talents. Forth, strengthen professional practice. Teaching in practical link is an important content in the training of developmental talents. Professional practice can only be strengthened. It seems especially important for some majors of science and engineering. It is required 
to change previous traditional teaching methods, strengthen the practical consciousness of college students and realize significant improvement of their ability. Fifth, carry out social practice. In the process of carrying out social practical activities, normal classroom teaching time should not be occupied, while winter and summer vacations should be used for social practical activities. Institutions of higher learning should establish a productive examination and assessment mechanism so as to exert the important role of social practice in the training of developmental talents to the greatest extent. Sixth, pay attention to teach students in accordance with their aptitude. It is a requirement put forward for the personality development of young students in colleges and universities in fact. In the process of talent training, it cannot be in a rut. University education attaches great importance to create good opportunities for the growth of individual talents. Therefore, it is necessary to introduce tutorial system, implement nurture and training of academic idea and scientific thought for college students, impel them to understand cutting-edge knowledge of this subject and train their ability of independent scientific research. When college students start to touch professional courses, it is required to discover and train talents and positively guide them through classroom teaching, social practice and graduation thesis. It is necessary to encourage college students to read scientific and technical literatures correctly, participate in scientific research activities and write scientific research thesis and make them pay high attention to internal and external technical tendency, positively participate in various symposiums, preliminarily possess the potential quality of conducting scientific research during the period of study and lay a good foundation for their future development.

\section{Thinking on training mode of interdisciplinary talents}

Interdisciplinary talents mainly refer to new talents mastering the knowledge and ability of two or more majors (disciplines). Generally, interdisciplinary talents have three types as below: first, interdisciplinary talents crossing first-level discipline; second, interdisciplinary talents crossing second-level discipline; third, interdisciplinary talents focusing on one major with multidisciplinary knowledge. Interdisciplinary talents are different from specialized personnel and all-round persons. Specialized personnel refer to specialized talents who master narrow system knowledge and specialized skills of a certain major and are proficient in a major. All-round persons refer to specialized talents breaking traditional major mode and possessing wide basic disciplinary knowledge and abilities. Therefore, in terms of talent specification and inner quality, specialized personnel master only systematic knowledge and abilities in a professional field with simple structure. All-round persons refer to talents with diversified structures receiving wide basic education in a certain field, showing diversification trend in knowledge and ability structure and involving wide knowledge fields. Interdisciplinary talents refer to talents mastering complete knowledge system and abilities of more than two majors and possessing the quality of two or more majors closely related. It is worth mentioning that multidisciplinary knowledge possessed by interdisciplinary talents are not loose or unrelated, but are integrated. Thus, it becomes a trigger point of new thinking and comprehensive abilities.

Training mode of interdisciplinary talents can be summarized as below: first, implement the reform of credit system. Due to the constant development of socialist market economy with Chinese characteristics, the market has put forward new requirements for talent training. Students trained are required to possess both a specialty and relevant disciplinary knowledge and high comprehensive qualities, thus manifesting the demand for new multilayer and multi-specification talents. With credit system, students can enjoy a high freedom in course selection and learn under the competitive teaching environment and elastic management mechanism. This provides a strong institutional guarantee for colleges to optimize various educational resources and train multilayer talents according to market demands. After the implementation of credit system, various limitations on majors can be broken, which is good for college students to select courses in different departments and majors under the situation of spare energy of learning and train more and better interdisciplinary talents. Second, carry out the teaching of major, minor, second major and second degree system. That 
is to say, college students minor in other specialized courses on the basis of completing major specialized courses. Once they obtain credits specified by minor, they can obtain the minor certificate. If college students meet graduation conditions of other majors, second major graduation certificate can be issued to them. Second Bachelor's degree can be granted to students meeting conditions of interdisciplinary professional degree. Such form provides a more flexible selection mode for the training of interdisciplinary talents and provides more approaches for the learning of college students and can improve their employment competitiveness. Third, implement cross-institutional course selection. Institutions of higher learning subject to joint school running should have their own dominant specialties and open the best learning resources to other colleges and universities. In this way, colleges and universities can exert their overall advantages and school-running effectiveness and improve the quality of teaching and education. Meanwhile, it is conducive to the training of interdisciplinary talents. Currently, a lot of international and domestic famous institutions of higher learning have conducted positive explorations in this aspect and been committed to training interdisciplinary talents with high quality. For example, Europe has formed European college credit transformation system and American Harvard University, Yale University and Massachusetts Institute of Technology etc. have realized mutual recognition of credit after the implementation of joint school-running, thus providing a wider talent training platform for college students.

\section{Thinking on training mode of innovative talents}

The judgment standard of innovative talents is not their occupation, status and educational background, but is their ability of innovation and whether they actually regard innovation as their own duty, whether they are good at learning and practice and whether they have made outstanding innovative achievements. Specifically speaking, innovative talents must meet four conditions: first, innovative awareness and ability; second, profound basic knowledge and three-dimensional knowledge structure; third, good abilities of planning, organization, management and coordination; forth, will of braving danger and persevering and characters of working tenaciously and being brave in innovation. Qualities and abilities above are connected with each other and are important qualities that must be possessed by innovative talents as well as important basis for exerting the innovation capability of talents.

Training mode of innovative talents can be summarized as below: first, form innovative educational concept. It is required to transform the traditional educational view centering in knowledge instruction and pay attention to train the spirit of innovation and innovative educational view. As an important educational concept, innovative education does not simply mean a specific teaching link and is not equal to practical teaching. Instead, it is manifested in the whole process of talent training in colleges and universities. To implement innovative educational thought, it is required to comprehensively build a more complete innovative educational mechanism through various links in and out of class. Teachers should use various opportunities to guide college students to participate in practice, encourage them to express their own ideas boldly and communicate and discuss with others positively and actively, and use various opportunities of experiment and internship to guide students to make explorations more consciously and actively. Second, endeavor to construct richer college campus culture. Contemporary college student associations have developed into an important educational link helping college students to form healthy and beneficial interests and hobbies and promoting their healthy growth. They have provided a good space for college students' free development and self-education and become a vital second classroom of college students. To further strengthen the function of second classroom, institutions of higher learning should strengthen the construction of extracurricular teaching system in the process of talent training and fully use various activities such as specialist seminar, debating discussion and sports competition, thus achieving corresponding results. Third, form a new teaching mode conducing to training innovative talents. Current teaching modes in colleges and universities generally lack various educational views, systems and methods required for the training of innovative talents. Currently, the key link of educational talent view and quality view of institutions of higher learning is the training 
and cultivation of batches of high-quality talents with the spirit of innovation and innovation capability. New teaching mode specific to innovative talents should use innovative teaching theory to guide the specific teaching practice of innovative talents, thus establishing a relatively stable college teaching organization mode. Positive exploration of innovative talent training mode in institutions of higher learning can provide good inspirations for the reform of college education and teaching and innovative talent training in China currently. The spirit of innovation of college students comes from the great interest in exploring the unknown world. Innovative education should start with the training of problematic consciousness of college students and endeavor to encourage college students to raise corresponding questions. This requires the implementation of reform and transformation of single instilling-type teaching method in the traditional sense into benign interaction between teachers and students in the teaching process. In the process of classroom teaching in institutions of higher learning, teachers should change into common participators from instructors, fully respect the dominant position of college students and positively encourage them to participate in classroom discussion and raise doubts boldly so as to train their comprehensive abilities of discovering, analyzing and solving problems more positively and actively. As the period of knowledge update constantly decreases, the knowledge of each discipline is highly divided and the new feature of penetration of multiple disciplines occurs. This requires institutions of higher learning to reform course teaching system correspondingly. It is required to not only strengthen the construction of basic courses, make college students have solid foundation and improve their literary accomplishments such as cultural quality and cultural taste, but also add optional courses and allow them to obtain more and wider knowledge contents.

\section{Conclusion}

The essence of training of developmental, interdisciplinary and innovative talents is the reform of talent training mode. Colleges and universities have been conducting explorations of talent training mode and achieved corresponding results. However, under the new situation, how should institutions of higher learning explore a new mode meeting talent training objectives of colleges and universities and their characteristics according to their school-running advantages and characteristics and the talent demand in the current market is a major issue of thinking. For the training of developmental, interdisciplinary and innovative talents, the author thinks that we should free our mind and endeavor to explore in reform and form modern talent training objectives meeting the need of the current society, which is an important premise of the comprehensive implementation of reform. It is required to establish a strong quality guarantee mechanism according to training objectives and train more and better talents.

\section{Acknowledgments}

The name of this topic is: Research on Training System of Interdisciplinary and Innovative Technical Talents - Take Marketing in Our College for Example, topic number: z201307

\section{References}

[1] Wu Baogui: Practical Thinking on Training of Innovative Talents, Journal of Shanxi University of Finance and Economics (Higher Education Edition), 2008(3).

[2] Yu Jianping: Train Developmental Talents and Reconstruct College Education System, Chinese Out-of-school Education, 2009(8).

[3] Zhang Zhichao: Brief Discussion on Training of Interdisciplinary Talents in Colleges and Universities, Journal of Tianjin Institute of Financial and Commercial Management, 2010(3). 
[4] Lin Zhong, Feng Ruiqin, Luo Liang: Essence of Independent Study, Cooperative Study and Inquiry Learning and Their Relationship, Journal of Beijing Normal University (Social Sciences Edition), 2011 (6)

[5] Cheng Peng: Thinking Triggered by Comparison of Training Modes of Innovative Talents in Chinese Colleges and Universities, Science and Technology Innovation Herald, 2011(9). 